\title{
Experimental analysis of flat plate solar air collector efficiency
}

\author{
Amir Hematian, YahyaAjabshirchi and Amir Abbas Bakhtiari \\ Agricultural Machinery Department, University of Tabriz, Iran \\ bakhtiari@tabrizu.ac.ir
}

\begin{abstract}
In the present study, a flat plate solar air collector is used for research purposes. The absorber of solar collector made by steel plate with an area of $2 \times 1 \mathrm{~m}^{2}$ and thickness of $0.5 \mathrm{~mm}$ in the form of window shade has been developed for increasing the air contact area. The surface of absorbent plate was covered by black paint. To insulate the collector, the glass wool with the thickness of $5 \mathrm{~cm}$ was used. The experiments on the efficiency were conducted for a week during which the atmospheric conditions were almost uniform and data was collected from the collector. The results of the collector efficiency in the natural and forced convection were evaluated and their graphs were plotted. The results showed that the collector efficiency in forced convection was lower, but the low temperature difference between inlet and outlet of the collector decreased its heat loss. In addition, the average air speed in forced convection was about $21 \%$ higher than the natural convection.
\end{abstract}

Keywords: Flat plate collector, Solar radiation, Efficiency.

\section{Introduction}

The sun is the most powerful heat generator with which neither of the heat sources created by mankind can compete. Annually, the solar energy obtained by earth is 15000 as much as the power industry of the whole world can produce. It means that only a tiny part of solar energy is used for the sake of mankind (Aboltinset al., 2009).

Solar collectors are the key component of active solar-heating systems. They gather the sun's energy, transform it's radiation into heat, and then transfer that heat into a fluid (usually water or air). The solar thermal energy can be used in solar water-heating systems, solar pool heaters, and solar space-heating systems. There are a large number of solar collector designs that have turned out to be functional. These designs are classified in two general types of solar collectors (Struckmann, 2008).

- Flat-plate collectors - the absorbing surface is approximately as large as the overall collector area that intercepts the sun's rays.

- Concentrating collectors - large areas of mirrors or lenses focus the sunlight onto a smaller absorber.

Flat-plate collectors are the most common solar collector for solar water-heating systems in houses and solar-heating spaces. A typical flat-plate collector is an insulated metal box with a glass or plastic cover (called the glazing) and a dark-colored absorber plate. These collectors heat liquid or air at temperatures less than 353.15 oK (Struckmann, 2008).

Flat plate solar collectors are classified into (Rhushi Prasad et al., 2010)

- Water-type (hydronic) collectors - using water as the heat-transfer fluid, and

- Air-type collectors - using air as the heat-transfer fluid.

The sun as the alternative energy source is progressively used in the national economics. One of the simplest practical applications of the sun is the air-heating collector which is simple to make, cheap to exploit, ecologically friendly and widely used, particularly in agricultural production drying (Aboltinset al., 2009).

Solar air collectors are simple deviceswhich heat air by utilizing solar energy and which are employed in many applications requiring low to moderate temperatures below $333.15^{\circ} \mathrm{K}$, such as crop drying and space heating. The principal types of these collectors are: the single passes with front duct, rear duct, double duct and double pass (Forsonet al., 2003).

The main drawback of flat plate absorber air collectors is the low heat transfer coefficient which results in lower thermal efficiency. If the area available for heat transfer is not greater than the projected area of the absorber, the absorber becomes unnecessarily hot which in turn leads to higher heat loss (El-Sawiet al., 2010; Yeh\& Lin, 1996).

The efficiency of the solar collector depends on the collector covered material; absorber and it's place in the collector and air velocity in the collector (Lauvaet al., 2006; Palabinskiset al., 2008). The main efficiency parameter of a solar collector is the air heating degree chosen as the criterion of efficiency in this study (Aboltinset al., 2009).

Certainly, the air temperature growth in the collector depends on the climatic conditions (wind, clouds, ambient air temperature etc.), covered and absorber materials of the collector and it's cleaning (Aboltinset al., 2009).

The evaluation of the thermal performance of solar air collectors is crucial for the proper design and sizing of the collector for a given application (El-Sawiet al., 2010; Karim\&Hawlader, 2006).

The research work of air solar collectors started more than ten years ago at the Latvian Agricultural University by prof. E. Berzins (Berzinšet al., 1998). The
Research article

(C)Indian Society for Education and Environment (iSee)
"Solar air collector" http://www.indjst.org
Amir Hematian et al. Indian J.Sci.Technol. 
investigations are directed at grain drying with solar collector heating air.

The term diathermanous is applied to materials capable of transmitting radiant energy, including solar energy. From the standpoint of the utilization of solar energy, the important characteristics are reflection, absorption, and transmission. The first two should be as low as possible and the latter as high as possible for maximum efficiency. According to the law of conservation of energy, the relationship between the absorbed, reflected and transmitted energy is:

$\alpha+\rho+\tau=1$

where, $\alpha$ is the solar absorptance, i.e. the fraction of the incident solar radiation absorbed by a substance; $\rho$ is the solar reflectance, i.e. the fraction of the incident solar radiation reflected by a surface; $\tau$ is the solar transmittance, i.e. the fraction of the incident solar radiation transmitted through a non-opaque substance (Rhushiprasadet al., 2010).

A parametric study on the thermal performance of a solar air collector with a v-groove absorber has been investigated by Liu et al. (2007a). The results show that the v-groove collector has a considerably superior thermal performance to the flat-plate collector. Also, in Liu et al. (2007b) the thermal performance of crosscorrugated and v-groove solar air collectors has been compared under a wide range of configuration and operating conditions. It is found that cross-corrugated collectors are superior to $\mathrm{v}$-groove ones for all the configurations and operating conditions considered, confirming that the use of the transversely positioned wavelike bottom plate, in cross-corrugated collectors improves the thermal performance.

The integrated solar collector is considered to be a promising direction for increasing the economic feasibility of low-temperature solar systems for heating water in domestic and industrial applications by Chen et al. (2010). The results indicated that the heat transfer ability is significantly improved by using paraffin with aluminum foams and the temperature difference between the frame and liquid paraffin cannot be ignored during the melting/solidifying process. Luoet al. (2010) theoretically studied the optimum heat source temperature for maximizing solar cooling coefficient of performance (COP) of a novel solar adsorption air-conditioning system (SAACS). The simulation results reveal that the solar cooling COP of the SAACS with evacuated tube collector can exceed 0.25 with optimum heat source temperature. Ghaliet al. (2011) model and optimize the operation of a combined air conditioning unit and solar distiller still to enhance distillate output and system performance to meet a specified cooling load and fresh water needs of a residential application.

Many researchers have studied collector and performance analysis to determine the system application such as Asaadet al. (2005) on heat pipe and direct heat exchange solar louvre collectors, Riffatet al. (2005) on hybrid heat-pipe solar collector, Yutong\& Yang (2010) on open-cycle solar collector/regenerator using liquid desiccant, Yang et al. (2009) on solar collector oscillatingflow heat pipe, MohseniLanguriet al. (2011) on doublepass solar air heater, Mohanrajet al. $(2008,2010)$ on direct expansion solar assisted heat pump, Grena (2011) on solar trough collector, Al-Nimret al. (2011) on integrated direct absorption self-storage solar collector.

The main objective of the present study is to investigate the application of window shade as thermal absorber plate in solar air collectors. This paper provides a description on the design and construction of a solar air collector and computes it's efficiency experimentally. This study helps to improve the efficiency ofsolar air collectors.

\section{Materials and methods}

\section{Experimental setup}

To carry out the experimental analysis, an active collector was used with the size of $2 \times 1 \times 0.15 \mathrm{~m}$. The wall of the collector is made from iron profile insulated by glass wool with the thickness of $5 \mathrm{~cm}$. The absorber plate is made from steel with the thickness of $0.5 \mathrm{mmpainting}$ the black and the sleek glass with a thickness of 4 mmused as a screen transparent collector cover. In order to decrease heat loss through the absorber plate, it was insulated underneath by glass wool with $5 \mathrm{~cm}$ thickness. To increase the contact surface of the absorber plate with

Figure 1. Schematic cross section of collector

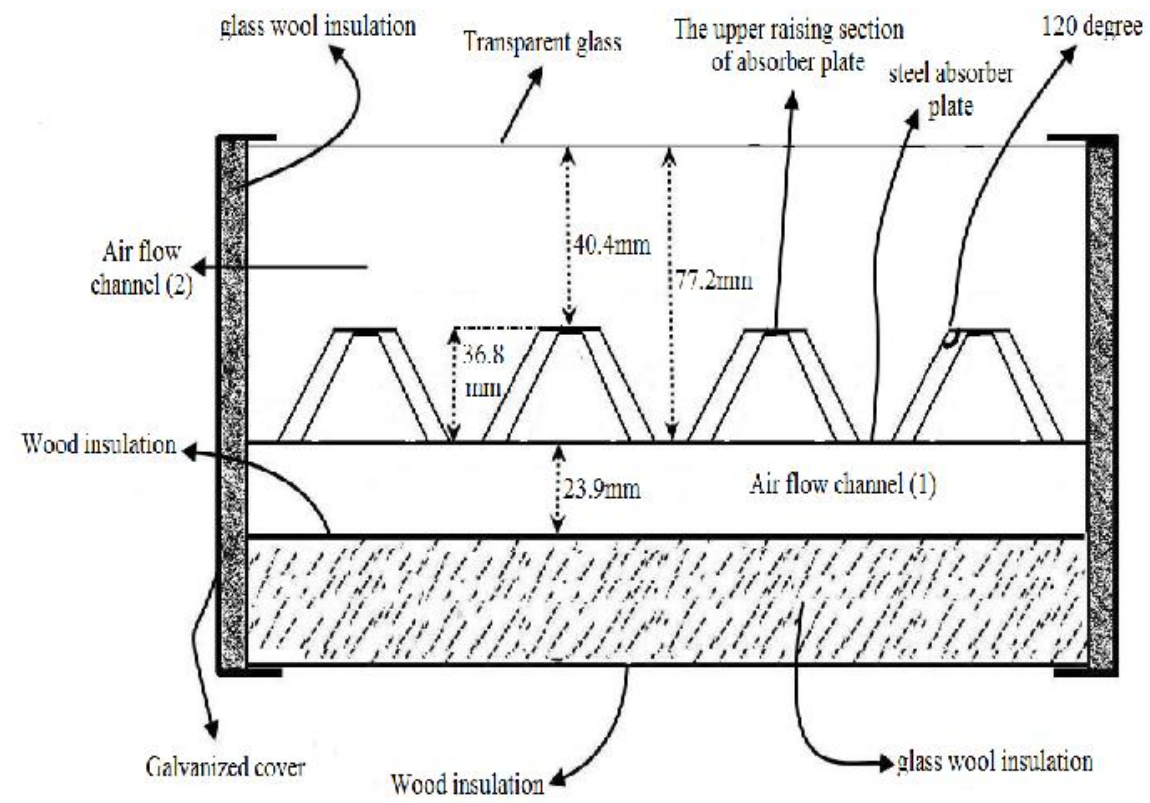

"Solar air collector"

http://www.indjst.org
Amir Hematian et al. Indian J.Sci.Technol. 
Table 1.The average values of calculation and measuring parameters in natural

hot air where flow in the collector, it's surface was designed in venetian form as it is illustrated in Figure 1. Air flow simultaneously occurred through the channel 1 (under the absorber plate) and the channel 2 (over the absorber plate).

Three temperature sensors (LM35) were installed with a specific distance from each other in the outlet of collector. The temperature was measured four timesand it's average values was calculated in one hour. Moreover, a temperature sensor was used to measure the inlet temperature in the entrance of the collector.The collector was positioned in the 29.5 degrees latitude in north-to-south direction in an open area. The tests with the solar collector system were carried out for seven days, from 18 to 24 June 2011 and 12 hours per day (from 8 a.m. to 8 p.m. local time). The collector was studied according to the natural and forced convection.

The experiments on the efficiency were conducted for a week during which the atmospheric conditions were almost uniform and data was collected from the collector. Study was performed in a time period in which the weather was clear were the case study was carried out. Also, the data of radiant energy and air speed collected had shown no significant differences in those days.

\section{Collector with natural convection}

In this case, the collector was evaluated without usingfan and it's average efficiency was recorded at different hours.

\section{Collector with forced convection}

In this case, a fan with a speed control system was designed and located on a board to stabilize the outlet temperature of the collector at the desired temperature ranges. Moreover, a small monitor was used to show the collector inlet and outlet temperatures. The required energy for the operation of the components of the controller circuit was provided through two solar panels with the size of $20 \times 15$ $\mathrm{cm}^{2}$ and they each had a $5 \mathrm{~W}$ power.Voltage, amperage and power the fan were $12 \mathrm{~V}, 0.48 \mathrm{~A}$ and $5.76 W$ respectively.

\section{Efficiency calculation}

Thermal efficiency of solar collector systems is defined as the ratio of useful energy gain by the air to solar radiation incident on the absorber of solar collector (Hematianet al., 2012; Kurtbash\&Durmush, 2004)

$\eta=\frac{Q_{\text {useful }}}{Q} \times 100$
Table 2. The average values of calculation and measuring parameters in forced convection. The surface area of the collector $=2 \mathrm{~m}^{2}$

\begin{tabular}{|c|c|c|c|c|c|c|c|}
\hline $\begin{array}{l}\text { local } \\
\text { time }\end{array}$ & $\begin{array}{c}\dot{m} \\
(K g / s)\end{array}$ & $\begin{array}{c}C_{p} \\
\left(\mathrm{~J} / K g .{ }^{\circ} \mathrm{K}\right)\end{array}$ & $\begin{array}{c}\Delta T \\
(\diamond K)\end{array}$ & $\begin{array}{c}I_{\beta} \\
\left(W / m^{2}\right)\end{array}$ & $\begin{array}{l}\text { Quseful } \\
(W)\end{array}$ & $\begin{array}{c}Q \\
(W)\end{array}$ & $\begin{array}{c}\eta_{\text {Collector }} \\
(\%)\end{array}$ \\
\hline $8-9$ & 0.015 & 1003 & 16.6 & 949.5 & 249.7 & 1899 & 13.1 \\
\hline $9-10$ & 0.018 & 1 & 15.4 & 1032.9 & 278 & 2065.8 & 13.5 \\
\hline $10-1$ & 0.02 & & 13.2 & 1108.9 & 317 & & 14.3 \\
\hline $11-12$ & 0.031 & & 13.1 & 1184.4 & 407.3 & 2368.8 & 17.1 \\
\hline 12- & 0.0 & & 12 & 1200.8 & 397.2 & 240 & 16.5 \\
\hline $13-14$ & 0.04 & 1003 & 12.2 & 1147.8 & 489.5 & 2295.6 & 21.3 \\
\hline $14-1$ & 0.035 & 1003 & 11.7 & 1097.2 & 410.7 & 2194.4 & 18.7 \\
\hline 15- & & & 1 & 1017.3 & 391.2 & 2034.6 & 19.2 \\
\hline $16-17$ & 0.029 & 1003 & 14 & 918.4 & 407.2 & 1836.8 & 22.2 \\
\hline $17-18$ & 0.025 & 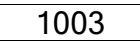 & 14.8 & 830.4 & 371.1 & 1660.8 & 22.3 \\
\hline 18- & & & 17 & 672.1 & 375.1 & 1344.2 & 27.9 \\
\hline $19-20$ & 0.019 & 1003 & 17 & 589.5 & 323.9 & 1179 & 27.5 \\
\hline
\end{tabular}

The values of $C_{p}$ have extracted from the thermodynamic tables (Malekzadeh\&KashaniHesar, 2004) 
surface of the solar collector $\left(m^{2}\right)$. The efficiency $(\eta)$, in the solar air collector is dependent on the air heating degree $(\Delta \mathrm{T})$, solar radiation $\left(I_{\beta}\right)$, rate of air mass flow $(\dot{m})$, type and place of absorbers.

\section{Result and discussion}

Determining collector efficiency in natural convection

Table 1 , shows the rate of air mass flow $(\dot{m})$, the specific heat capacity of the air at constant pressure $\left(C_{p}\right)$, the temperature difference between the inlet and outlet air $(\Delta \mathrm{T})$, the solar radiation per square meter $\left(I_{\beta}\right)$, the

Figure 2. The average efficiency of the collector in natural convection

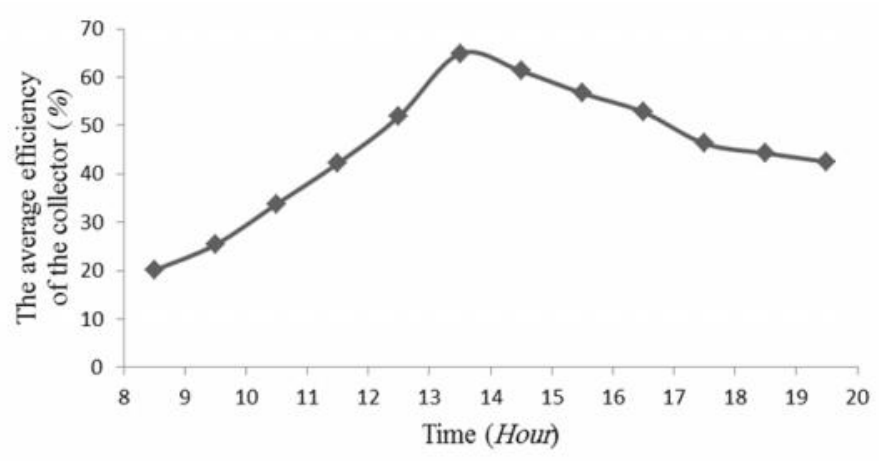

Figure 3. The average efficiency of the collector in forced convection

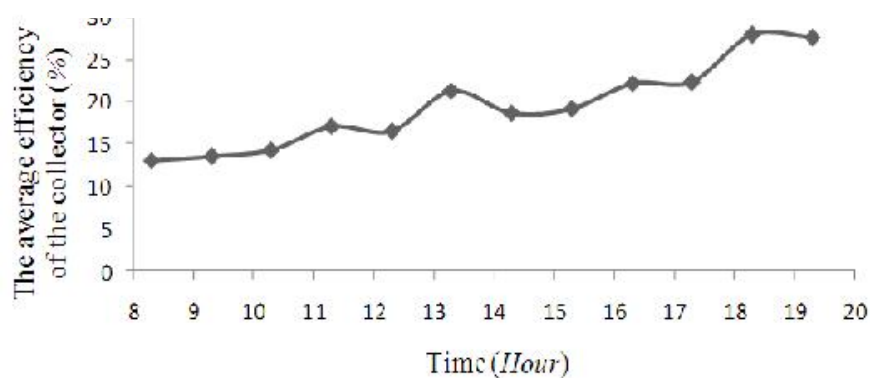

Figure 4. The average rate of air mass flowin the testing days

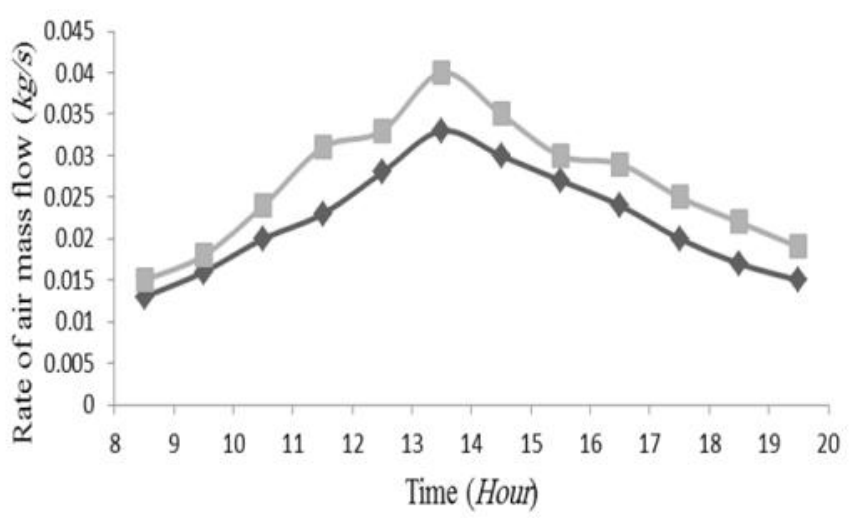

$\rightarrow$ Natural Convection $\quad-$-Forced Convection value of useful energy of the collector ( $\left.Q_{\text {useful }}\right)$ which is obtained from equation 3 , the value of total energy of the collector $(Q)$ which is obtained from equation 5 and collector efficiency which is obtained from equation 2 , all during the testing hours.

According to Table 1 and Figure2, the most collector efficiency occurred atthe time of 13-14 in natural convection. This reason can be explained by the maximum air temperature difference between the inlet and outlet of collector and also the higher rate of mass flow. As it shown in Figure 2, because of the energy storage by the absorber plate during a day, collector efficiency in the finishing hours was more than the early hours of a day.

Determining collector efficiency in forced convection

As it can be seen in Table 2 and Figure 3, in the tests carried out in different testing days, the average efficiency of the solar collector has an ascending tendency, and only in some intervals, i.e., the times of $12-13,14-15$ and 19-20 there are descending streak in it. The streaks are due tosudden changes inweather conditions and cloudiness which affect the average inlet and outlet temperatures and also cause a decrease in the temperature difference between the inlet and outlet of collector. By decreasing the outlet air temperature, the speed of outlet air and consequently the rate of air mass flow is reduced and as a result the efficiency is decreased (Hematianet al.,2012).

Outlet air temperature within the specified periods and certain time interval was fixed at the innovative design of control systems with forced convection. This property is used in various applications including solar dryer. It also caused heat loss reduction due to lower air temperature difference between inside and outside of collector. Considering the results of the collector outlet temperature, it is higher in natural convection, but the mass flow rate curve (Figure 4) showed that the average air speed in forced convection was about $21 \%$ higher. This case can be useful in the solar dryer for drying juicy fruits slices. It can be explained by two points: first, the relatively high speed is necessary for transporting water vapour of fruits and second, they don't require high temperatures. If the air temperature in the drying time is high, a thin firm layer is formed on juicy fruits slices surfaces. As a result, evaporation process and drying operation become difficult.

In this research, the collector efficiency in both natural and forced convection was calculated. According to the results, it is concluded that collector efficiency in case of natural convection was more than forced convection, but it's heat loss is high due to the large temperature difference between inside and outside of the collector. The collector efficiency in forced convection was lower, but the low temperature difference betweeninside and outside of the collector decreased it's heat loss. Based on the purpose of designing control system for forced convection that stabilized the collector
Research article

CIndian Society for Education and Environment (iSee)
Amir Hematian et al. Indian J.Sci.Technol. 
outlet temperature in specified ranges, temperature difference between inlet and outlet of collector and accordingly it's $Q_{\text {useful }}$ and efficiency decreased compared to the natural convection. The flow of air was crossed through shutters as considering the special design of this absorber. This method provided larger surface area and also could cause the output air warm faster.

\section{Conclusions}

In this paper, a solar collector has been designed and developed. The collector was studied in both the natural and forced convection. According to the above-mentioned results, it has been found that the collector provided with natural convection gave high efficiency when compared to collector with the forced convection. However, the heat loss in the forced convection is considerably lower than the natural convection. Furthermore, the results showed that the average air speed in the forced convection was about $21 \%$ higher than the natural convection which is important in solar dryers.

\section{References}

1. Aboltins AJ, Palabinskis A, Lauva and G Ruškis (2009) Investigation of air solar collector efficiency. Engg. Rural Develop., Jelgava, Latvia, 28-29 May, pp: 176-181.

2. Al-Nimr MA, Khuwaileh B and M Alata (2011) A novel integrated direct absorption self-storage solar collector. Intl. J. Green Energy. 8(6), 618-630.

3. Asaad M, Abu-Zour SB, Riffat R and Wilson R (2005) Comparison between heat pipe and direct heat exchange solar louvre collectors. Intl. J. Green Energy. 2(4), 353-364.

4. Berzinš E, Immermanis E and Lukevics E (1998) The results of investigations of model of air solar collector. Nr16(293), 54-57.

5. Chen Z, Gu M, Peng D, Peng C and Wu Z (2010) A numerical study on heat transfer of high efficient solar flat-plate collectors with energy storage. Intl. J. Green Energy. 7(3), 326-336.

6. El-Sawi AM, Wifi AS, Younan MY, Elsayed EA and Basily BB (2010) Application of folded sheet metal in flat bed solar air collectors. Appli. Thermal Engg. 30, 864871.

7. Forson FK, Nazha MAA and Rajakaruna H (2003) Experimental and simulation studies on a single pass. double duct solar heater. Energy Conversion \& Manage. 44, 1209-1227.

8. Ghali K, Ghaddar N and Alsaidi A (2011) Experimental and theoretical study of an optimized integrated solar desalination and air conditioning unit. Intl. J. Green Energy. 8(1), 81-99.

9. Grena R (2011) Efficiency gain of a solar trough collector due to an ir-reflective film on the non-irradiated part of the receiver. Intl. J. Green Energy. 8(7), 715-733.

10. Hematian A, Ajabshirchi $\mathrm{Y}$, Behfar $\mathrm{H}$ and Ghahramani $\mathrm{H}$ (2012) Designing, construction and analysis of speed control system of the fan with PV feeding source in an air solar collector. Modern Appl. Sci. 6(1), 136-144.

11. Karim MA and Hawlader MNA (2006) Performance evaluation of a v-groove solar air collector for drying applications. Appl. Thermal Engg. 26, 21-130.
12. Kurtbash I and Durmush A (2004) Efficiency and exergy analysis of a new solar air heater. Renewable Energy. 29(9), 1489-1501.

13. Lauva A, Aboltins A, Palabinskis $\mathrm{J}$ and KarpovaSadigova N (2006) Comparative studies of the solar material collector. Proc. $5^{\text {th }}$ Intl. Sci. Conf., Engg. Rural Develop., J elgava, Latvia, 18-19 May, pp: 90-94.

14. Liu T, Lin W, Gao W and Xia C (2007b) A comparative study of the thermal performances of cross-corrugated and v-groove solar air collectors. Intl. J. Green Energy. 4(4), 427-451.

15. Liu T, Lin W, Gao W, Luo C, Li M, Zheng Q and Xia C (2007a) A parametric study on the thermal performance of a solar air collector with a v-groove absorber. Intl. J. Green Energy. 4(6), 601-622.

16. Luo H, Wang RZ and Dai YJ (2010) Optimum matching of heat source temperature to a solar adsorption airconditioning system for maximum solar cooling coefficient of performance. Intl. J. Green Energy. 7(1), 91-102.

17. MalekzadehGh and KashaniHesar MH (2004) Fundamental of thermodynamic (translation in Persian). Nima Publi., Iran.

18. Mohanraj M, Jayaraj S and Muraleedharan C (2008) Modeling of a direct expansion solar assisted heat pump using artificial neural networks. Intl. J. Green Energy. 5(6), 520-532.

19. Mohanraj M, Jayaraj S and Muraleedharan C (2010) Exergy assessment of a direct expansion solar-assisted heat pump working with $\mathrm{r} 22$ and $\mathrm{r} 407 \mathrm{c} / \mathrm{lpg}$ mixture. Intl. J. Green Energy. 7(1), 65-83.

20. MohseniLanguri $\mathrm{E}$, Taherian $\mathrm{H}$, Hooman $\mathrm{K}$ and Reisel $\mathrm{J}$ (2011) Enhanced double-pass solar air heater with and without porous medium. Intl. J. Green Energy. 8(6), 643-654.

21. Palabinskis J, Lauva A, Aboltinš $A$ and KarpovaSadigova N (2008) Movable air solar collector and its efficiency. $7^{\text {th }}$ Intl. Sci. Conf., Engg. Rural Develop., Jelgava, Latvia, 29-30 May, pp: 51-56.

22. Rhushi Prasad P, Byregowda HV and Gangavati PB (2010) Experiment analysis of flat plate collector and comparison of performance with tracking collector. Eur. J. Sci. Res. 40(1), 144-155.

23. Riffat $S B$, Zhao $X$, Boukhanouf $R$ and Doherty PS (2005) Theoretical and experimental investigation of a novel hybrid heat-pipe solar collector. Intl. J. Green Energy. 1(4), 515-542.

24. Struckmann F (2008) Analysis of a flat-plate solar collector. Project report (Heat and Mass Transport). Lund Univ., Lund, Sweden.

25. Yang Y, Xian H, Liu D, Chen C and Du X (2009) Investigation on the feasibility of oscillating-flow heat pipe applied in the solar collector. Intl. J. Green Energy. 6(5), 426-436.

26. Yeh HM and Lin TT (1996) Efficiency improvement of flat-plate solar air heaters. Energy. 21(7), 435-443.

27. Yutong $L$ and Yang $H$ (2010) Experimental study of an open-cycle solar collector/regenerator using liquid desiccant for air conditioning. Intl. J. Green Energy. 7(3), 273-288.
Research article

COIndian Society for Education and Environment (iSee)
"Solar air collector" http://www.indjst.org
Amir Hematian et al. Indian J.Sci.Technol. 